\title{
RACIOCÍNIO HIPOTÉTICO-DEDUTIVO RELATIVO À FLUTUAÇÃO
}

\author{
Sonia Krapas, Inst. Física, UFF \\ Maria Célia Dibar Ure, Fac. Ciências Exatas e Naturais, Univ. Buenos Aires \\ Luiza Rodrigues de Oliveira, Fac. Educação, USP
}

O objetivo do trabalho é estudar as estratégias adotadas frente à tarefa de escolha de hipóteses relativa ao fenômeno de flutuação. Os datos foram obtidos a partir de entrevistas com crianças e de questionários com adultos. Na análise dos resultados foram contempladas as relações das estratégias com a idade, com a forma e com o conteúdo das hipóteses. A precocidade da estratégia de falseamento correto foi atribuída a diferenças nos procedimentos mentais utilizados por crianças e adultos. Tratamentos estatísticos dos dados confirmam alguma relação entre as estratégias e a forma e o conteúdo das hipóteses. São apontadas contribuições para o ensino de ciências.

\section{INTRODUÇÃO}

A apropriação da teoria piagetiana na área de Educação em Ciências vai inicialmente no sentido de mostrar as possíveis limitações na aprendizagem devidas ao estágio do pensamento em que se encontra o aprendiz. É nessa linha de raciocínio que estão os trabalhos de Lawson e colaboradores em meados da década de setenta. Como um bom exemplo, tem-se o artigo cujo título, bastante expressivo, é: "Conceitos abstratos deveriam ser ensinados antes das operações formais?" (Lawson e Renner 1974). Pozo (1987) discute, de um modo muito interessante, as implicações para o ensino de ciências dessa posição de onipotência do pensamento formal.

Levantamentos sobre o nível de desenvolvimento mental com base nos trabalhos da escola de Genebra apresentam resultados surpreendentes: apontam para a ausência da capacidade hipotética-dedutiva, característica do pensamento formal, mesmo em adultos escolarizados tais como estudantes universitários. Nesse panorama, surgem trabalhos como os de Pozo (1988), Castorina (1985) e Carretero (1980), que evidenciam a dependência que o pensamento formal tem do conteúdo da tarefa a ser realizada.

Paralelamente a esses trabalhos com adultos, estudos empíricos com crianças também têm sido feitos com o objetivo de verificar como elas utilizam o pensamento formal. Levantando problemas de aprendizagem em ciências, Carretero (1979:7) resume suas preocupações: "Como as crianças utilizam, quando têm ocasião, a comprovação de hipóteses, que é uma das partes essenciais do método científico? Em que idade se usa, sem problemas, a comparação, modificação e seleção de hipóteses? Que dificuldades aparecem com mais freqüência quando as crianças enfrentam uma formulação hipotética sobre um conteúdo científico?". 
$\mathrm{Na}$ década de noventa, numa tentativa de diálogo entre a Psicologia Cognitiva e a Educação em Ciência, Carretero e colaboradora (Baillo e Carretero (1996:81-82) retomam essa problemática sob a ótica da mudança conceitual, colocando questões sobre o uso do raciocínio lógico-matemático: "Sem dúvida, uma das questões essenciais no estudo da possibilidade da dita mudança [conceitual] em crianças e adultos é precisamente em que medida a capacidade de raciocínio dos sujeitos pode influenciar nessa mudança. Isto é, ao se raciocinar melhor, levar-se-á cabo com mais facilidade um processo de mudança conceitual?".

A atualidade do tema nos remeteu aos primeiros trabalhos de Carretero. (1979 e 1984) sobre o desenvolvimento do pensamento hipotético-dedutivo. Os resultados mostram respostas que sugerem o uso, por crianças na faixa dos 7 anos de idade, do que ele denomina de 'estratégia de falseamento'. No linguajar piagetiano essa estratégia consistiria em falsear uma hipótese sob a forma de um enunciado condicional (Piaget 1952). Dessa maneira, a criança estaria mostrando que é capaz de discriminar uma hipótese na forma de condicional de outras formas de enunciado. De acordo com a visão piagetiana, essa estratégia, própria a adolescentes e adultos, seria típica do pensamento formal, pois implica (mesmo que implicitamente) o uso e a discriminação das operações da lógica proposicional. Podemos, então, formular algumas questões:

- Como se justifica o aparecimento tão precoce da estratégia de falseamento, típica do pensamento formal?

- Em que medida o conteúdo e a forma das questões podem influenciar a escolha das estratégias?

O objetivo do presente trabalho é confirmar o aparecimento, nas diferentes faixas etárias, das estratégias propostas por Carretero e estudar, em detalhe, a estratégia de falseamento, tentando responder às questões acima.

Pondo de lado posições extremadas de onipotência do pensamento formal, não é possível deixar de admitir que as habilidades características do pensamento formal constituem um importante parâmetro para a compreensão do conhecimento científico. Assim, respostas às questões acima apresentam, de alguma forma, implicações para o ensino de ciências.

\section{METODOLOGIA}

\section{Amostra}

Os dados foram coletados a partir de entrevistas com crianças e de questionários com adultos. Sentimos necessidade de trabalhar com adultos, pois tínhamos percebido, no dia-a-dia, suas dificuldades em escolher contra-exemplos que falseiam uma hipótese, isto é, dificuldades em discriminar uma hipótese na forma de uma condicional de outras formas de enunciado. Para as entrevistas, nossa amostra se constituiu de 4 grupos de cinco crianças ${ }^{1}$ distribuídas pelas

\footnotetext{
${ }^{1}$ Por problemas ocorridos na coleta de dados (que trataremos em detalhe no decorrer do artigo), acrescentamos mais nove crianças à amostra. Isso explica por que na tabela 1 o número total de respondentes é 29 , enquanto nas outras tabelas esse número é 20.
} 
faixas de 5, 7, 9 e 11 anos $^{2}$. O questionário foi respondido por estudantes da escola média da rede pública estadual, estudantes universitários e professores da escola básica e média. $O$ número total de sujeitos foi de 250, mas, pelo fato de cada um deles ter respondido apenas à parte das questões, o número de respostas para cada questão variou de 80 a 110.

\section{A entrevista}

Introduzimos algumas modificações na coleta de dados em relação a Carretero, que realizou as entrevistas em duas etapas: uma com o objetivo de levantar as idéias das crianças e outra com o objetivo de destacar a lógica usada por elas. Preferimos um desenho experimental com uma única entrevista de duas partes. A primeira parte da entrevista foi feita nos moldes piagetianos, porém sem contra-sugestões habitualmente utilizadas pelo entrevistador. Essa parte constou da apresentação de objetos, alguns deles ocos, que tinham grande variação quanto ao peso, à densidade, porosidade e ao material de que eram constituídos. Foram eles: pedra-pomes, pedaço de madeira, prego, vela, giz, clipes e cilindros de madeira, alumínio e latão. Foi pedido à criança que separasse os objetos em dois grupos - os que bóiam e os que afundam - e que justificasse sua escolha. A criança era, então, convidada a testar experimentalmente sua hipótese e comentar os resultados. Em seguida, iniciava-se a segunda parte da entrevista, na qual era utilizada a mesma técnica de Carretero (1979; 1984), isto é ,a apresentação de hipóteses supostamente formuladas por outras crianças acerca da flutuação dos corpos:

- As coisas bóiam porque pesam pouco.

- As coisas bóiam porque são pequenas.

- As coisas bóiam porque são ocas.

- As coisas bóiam porque têm muita água.

A apresentação dessas hipóteses era feita oralmente, ao invés de por escrito tal como na pesquisa original. Depois dessa apresentação, os sujeitos mostravam ao experimentador se a frase era falsa ou verdadeira, não só verbalmente mas também empiricamente, utilizando os objetos disponíveis.

\section{O questionário}

Existem várias versões do questionário que foram compostas com uma série de perguntas retiradas dentre aquelas que apresentamos em anexo. Na parte a) dessas perguntas, foram apresentadas afirmações acerca das quais o sujeito foi convidado a se pronunciar sobre a veracidade ou falsidade, justificando sua resposta. A parte b) foi mais restritiva: pediu-se ao sujeito que escolhesse dentre três alternativas aquela que falseava a afirmação da parte a).

\footnotetext{
${ }^{2}$ Carretero trabalhou com crianças na faixa etária 7-17 anos. Recorremos a crianças de 5 anos porque estávamos interessadas em estudar o uso precoce da estratégia de falseamento.
} 
Como suspeitávamos que as respostas seriam dependentes do conteúdo das questões, no que concerne aos domínios de conhecimento envolvidos, apresentamos questões ora ligadas à flutuação ora ligadas ao cotidiano. Por exemplo:

- Tudo que é pesado afunda.

- Tudo que voa é ave.

Acreditávamos também que as respostas poderiam ser influenciadas pela forma na qual as questões eram apresentadas. Utilizamos enunciados com os conectivos tudo que ou porque. Por exemplo:

- Tudo que voa é ave.

- É ave porque voa.

\section{RESULTADOS}

\section{A entrevista}

Os sujeitos foram classificados de acordo com o tipo de explicação dada ao fenômeno da flutuação e de acordo com as estratégias usadas frente a cada hipótese supostamente formulada por outras crianças.

Com relação à explicação dada ao fenômeno da flutuação dos corpos, tínhamos a expectativa de que poderiam ocorrer as seguintes possibilidades: respostas baseadas no tamanho, no peso, na densidade, além de respostas animistas e morais (Piaget 1927; 1955). Entretanto, encontramos somente os tipos de respostas que estão apresentadas na TAB. 1, que cruza as explicações com a faixa etária.

TABELA 1 - Classificação dos sujeitos de acordo com a explicação sobre a flutuação dos corpos e de acordo com a faixa etária.

\begin{tabular}{|c|c|c|c|c|}
\hline \multirow[t]{2}{*}{ EXPLICAÇÕES } & \multicolumn{4}{|l|}{ IDADES } \\
\hline & cinco & sete & nove & onze \\
\hline $\begin{array}{l}\text { contraditória e/ou } \\
\text { moral }\end{array}$ & 2 & & & \\
\hline baseada no tamanho & 1 & & & \\
\hline baseada no peso & 2 & 8 & 8 & 6 \\
\hline não respondeu & 2 & & & \\
\hline
\end{tabular}

Passemos às estratégias apresentadas pelo sujeito frente às hipóteses de outras crianças. Tomamos por base a classificação utilizada por Carretero (1979; 1984): interpretação descritiva, comprovação com resistência ao falseamento, verificadora, falseamento mediante uma interpretação bicondicional do enunciado e falseamento correto.

Com interpretação descritiva, Carretero quer dizer que o sujeito não percebe o caráter hipotético do enunciado, isto é, ele descreve a situação sem tentar falsear ou comprovar a 
hipótese apresentada: "É como si estivesse raciocinando sobre uma frase que fosse unida por "e" em vez de unida por um nexo causal" (Carretero 1984:331). Não verificamos tal estratégia.

Com relação à estratégia de comprovação com resistência ao falseamento, Carretero afirma que os sujeitos "consideram a hipótese como tal, quer dizer, os sujeitos lhe outorgam um caráter de possibilidade e causalidade e dão os passos necessários para comprová-la. Mas quando encontram tipos de bolas [objetos utilizados na pesquisa de Carretero] que falseiam a hipótese, não aceitam a conclusão de que a hipótese é falsa" (Carretero 1984:331). Nos nossos dados, houve somente um caso: quando apresentamos a hipótese de que as coisas bóiam porque são ocas, a criança (sujeito 14, 7 anos) concordou com a hipótese e mostrou um cilindro que ela considerou oco e que, para sua surpresa, afundou. Pegou, então, o cilindro e concluiu que ele deveria estar cheio de água. A entrevistadora abriu o cilindro e a criança pôde constatar que o cilindro era de fato oco. Perplexa diante dessa constatação, a criança não entendeu que um cilindro oco possa afundar e perguntou: "Por que é pesado?".

Estratégia verificadora ocorre, segundo Carretero, quando os sujeitos só levam em conta os objetos que confirmam a explicação e ignoram os que demonstram que essa explicação é falsa:

O sujeito 3 (11 anos) diz que concorda com o enunciado As coisas bóiam porque pesam pouco. E mostra objetos leves que bóiam: vela, bloco de madeira fino, cilindro de madeira.

O sujeito 10 (9 anos) diz que concorda com o enunciado As coisas bóiam porque são ocas. E mostra um objeto oco que bóia: um tubo de plástico.

Carretero fala, ainda, de falseamento mediante uma interpretação bicondicional do enunciado quando os sujeitos afirmam que a hipótese é falsa, mas interpretam um enunciado que envolve uma implicação numa única direção (como são os enunciados $A$ porque $B$ ) como um enunciado que representa uma implicação dupla ou bicondicional (que seria considerar simultaneamente $A$ porque $B$ e $B$ porque $A$ ). Isso fica evidente quando a criança não toma 0 falseador correto para a hipótese sugerida ou quando as crianças apontam objetos que falseariam tanto a implicação numa direção como na direção oposta.

O sujeito 7 (9 anos) diz que não concorda com o enunciado As coisas bóiam porque são ocas. Mas pega tubo de plástico com água para falseá-lo, isto é, pega um objeto maciço que bóia, ao invés de tomar um oco que afunda.

O sujeito 14 (7 anos) diz que não concorda com o enunciado As coisas bóiam porque são pequenas. Pega um pedaço de pedra-pomes, que considera grande, e diz: "Então, como é que esse aqui tá boiando? Esse aqui é grandinho".

$\mathrm{Na}$ estratégia falseamento correto os sujeitos falseiam corretamente a hipótese interpretando-a como uma condicional:

O sujeito 12 (7 anos) diz que não concorda com o enunciado As coisas bóiam porque são pequenas. Pega o cilindro pequeno de alumínio e o tubo de plástico com água e diz: "tem coisa que é pequena e não bóia".

O sujeito 13 (7 anos) diz que não concorda com o enunciado As coisas bóiam porque são pequenas. E pega o cilindro pequeno de latão (objeto pequeno que afunda). 
Cabe, agora, fazer alguns comentários em relação a essa classificação. A estratégia de falseamento mediante uma interpretação bicondicional do enunciado seria aquela na qual o sujeito aponta tanto objetos que falseariam corretamente a hipótese como objetos que a falseariam incorretamente. Há outros sujeitos, no entanto, que só indicam objetos que falseiam incorretamente a hipótese. Esse fato levanta a hipótese de que, nesse caso, teríamos uma estratégia mediante uma interpretação condicional inversa do enunciado. Assim, preferimos designar essas estratégias como falseamento incorreto do enunciado.

A seguir, apresentamos as TAB. 2, 3, 4 e 5, que cruzam as estratégias com a faixa etária para as diferentes hipóteses apresentadas pelo entrevistador. Em não respondeu, incluímos tanto a falta de resposta como resposta contraditória ou incompreensível.

TABELA 2 - Distribuição dos sujeitos de acordo com as estratégias e a faixa etária frente à hipótese As coisas bóiam porque pesam pouco

\begin{tabular}{|l|c|c|c|c|}
\hline \multicolumn{1}{|c|}{ ESTRATÉGIAS } & \multicolumn{2}{l|}{} \\
\cline { 2 - 5 } & cinco & sete & nove & onze \\
\hline interpretação descritiva & & & & \\
\hline $\begin{array}{l}\text { resistência ao } \\
\text { falseamento }\end{array}$ & & & & \\
\hline verificação & 3 & 3 & 4 & 1 \\
\hline falseamento incorreto & & 1 & & \\
\hline falseamento correto & & & & 1 \\
\hline concorda sem verificar & & & & 3 \\
\hline não respondeu & 2 & 1 & 1 & \\
\hline
\end{tabular}

TABELA 3 - Distribuição dos sujeitos de acordo com suas estratégias e a faixa etária frente à hipótese As coisas bóiam porque são pequenas

\begin{tabular}{|l|c|c|c|c|}
\hline \multicolumn{1}{|c|}{ ESTRATÉGIAS } & \multicolumn{2}{l|}{} \\
\cline { 2 - 5 } & cinco & sete & nove & onze \\
\hline interpretação descritiva & & & & \\
\hline $\begin{array}{l}\text { resistência ao } \\
\text { falseamento }\end{array}$ & & & & \\
\hline verificação & 1 & & 1 & 1 \\
\hline falseamento incorreto & 1 & 1 & 2 & 1 \\
\hline falseamento correto & & 3 & 2 & 1 \\
\hline não respondeu & 3 & 1 & & 2 \\
\hline
\end{tabular}


TABELA 4 - Distribuição dos sujeitos de acordo com suas estratégias e a faixa etária frente à hipótese As coisas bóiam porque são ocas

\begin{tabular}{|l|c|c|c|c|}
\hline \multicolumn{1}{|c|}{ ESTRATÉGIAS } & \multicolumn{2}{l|}{} \\
\cline { 2 - 5 } & cinADES & sete & nove & onze \\
\hline interpretação descritiva & & & & \\
\hline $\begin{array}{l}\text { resistência ao } \\
\text { falseamento }\end{array}$ & & 1 & & \\
\hline verificação & 2 & 1 & 1 & 2 \\
\hline falseamento incorreto & & 1 & 3 & 1 \\
\hline falseamento correto & & & & 2 \\
\hline concorda sem verificar & & & & \\
\hline não respondeu & 3 & 2 & & \\
\hline
\end{tabular}

TABELA 5 - Distribuição dos sujeitos de acordo com as estratégias e a faixa etária frente à hipótese As coisas bóiam porque tem muita água

\begin{tabular}{|l|l|c|c|c|}
\hline \multicolumn{1}{|c|}{ ESTRATÉGIAS } & \multicolumn{1}{l|}{ IDADES } & nove & onze \\
\hline interpretação descritiva & cinco & sete & & \\
\hline $\begin{array}{l}\text { resistência ao } \\
\text { falseamento }\end{array}$ & & & & \\
\hline verificação & & & & \\
\hline falseamento incorreto & & 1 & & 2 \\
\hline falseamento correto & & & & 1 \\
\hline concorda sem verificar & & & & 1 \\
\hline usa outra hipótese & & & & \\
\hline não respondeu & 5 & 4 & & 1 \\
\hline
\end{tabular}

\section{O questionário}

Como estávamos interessados em estudar com mais detalhe a estratégia de falseamento, analisamos apenas tais estratégias no questionário ${ }^{3}$. As TAB. 6 e 7 sintetizam, respectivamente, as respostas dos sujeitos na parte a) e b) das questões referentes aos domínios de conhecimento oco, ave e pesado, e aos conectivos tudo que e porque.

\footnotetext{
${ }^{3}$ É por esse motivo que os números que aparecem nas tabelas 6 e 7 são sempre menores que o número de respostas para cada questão, que variou de 80 a 110. Foram descartados outros tipos de respostas tais como as que concordaram com a hipótese, discordaram da hipótese sem falseá-la ou as que apresentaram outra hipótese (em geral, a lei física que rege a flutuação dos corpos, já que tínhamos alunos universitários de áreas tecnológicas).
} 
TABELA 6 - número de falseamentos corretos e incorretos relativo à parte a) das questões

\begin{tabular}{|l|l|c|c|c|c|}
\hline \multirow{2}{*}{ ESTRATÉGIAS } & \multicolumn{5}{|l|}{ DOMÍNIO } \\
\cline { 2 - 6 } & & oco & ave & pesado & total \\
\hline falseamento incorreto & tudo que & 28 & 62 & 53 & 143 \\
\hline & porque & 13 & 11 & 47 & 71 \\
\hline falseamento correto & tudo que & 7 & 14 & 5 & 26 \\
\hline & porque & 28 & 56 & 14 & 98 \\
\hline
\end{tabular}

TABELA 7 - número de falseamentos corretos e incorretos relativo à parte b) das questões

\begin{tabular}{|l|l|c|c|c|c|}
\hline \multirow{2}{*}{ ESTRATÉGIAS } & \multicolumn{5}{|l|}{ DOMÍNIO } \\
\cline { 2 - 6 } & & oco & ave & pesado & total \\
\hline falseamento incorreto & tudo que & 49 & 58 & 55 & 162 \\
\hline & porque & 18 & 8 & 35 & 61 \\
\hline falseamento correto & tudo que & 26 & 22 & 54 & 102 \\
\hline & porque & 71 & 72 & 46 & 189 \\
\hline
\end{tabular}

\section{ANÁLISE DOS RESULTADOS}

A partir dos resultados, podemos destacar aspectos acerca das relações estratégia versus idade, estratégia versus forma das hipóteses e estratégia versus conteúdo das hipóteses.

\section{Estratégias versus idade}

$\mathrm{Na}$ faixa dos 5 anos, em todas as tabelas, pode-se verificar uma ausência de falseamento correto, resultado previsível, visto que se trata de crianças no nível de desenvolvimento pré-operatório. Por outro lado, é possível que crianças de 7, 9 e 11 anos, possivelmente no nível operatório, falseiem corretamente uma hipótese. A questão da precocidade dos corretos procedimentos de falseamento foi levantada pelo próprio Carretero, mas como Dibar Ure e Castorina (1989) muito bem apontam, não foi respondida por ele. Acreditamos que os processos mentais adotados pelas crianças são diferentes aos adultos. Talvez a criança tome uma espécie de "atalho". Então, vejamos: a afirmação As coisas bóiam porque são pequenas significa que a causa das coisas boiarem vem do fato de serem pequenas. O falseador dessa hipótese é um objeto pequeno que afunda. Como será que a criança descobre esse falseador? Acreditamos que ela se fixa na qualidade objeto pequeno e verifica (mentalmente) se a propriedade da flutuação se aplica aos objetos que considera pequenos. Nessa maneira de raciocinar, a procura de falseadores está fortemente vinculada ao conteúdo da hipótese apresentada: quanto maior a familiaridade com determinado conteúdo, 
mais facilmente são feitos falseamentos corretos. A imagem de objetos conhecidos flutuando ou afundando jogam um papel importante.

Como procede o adulto escolarizado? Vamos argumentar que sua forma de raciocinar reside em lidar com proposições, em oposição às imagens usadas pelas crianças. $\mathrm{O}$ adulto sabe, muitas vezes de forma inconsciente, que existem algumas possibilidades de resposta para o falseador procurado. Essas possibilidades são:

- Objetos pequenos que afundam

- Objetos grandes que flutuam

- Objetos pequenos que afundam ou objetos grandes que flutuam.

No entanto, a resposta certa deverá acarretar uma escolha consciente de uma das três possibilidades. Acreditamos que, quando essas possibilidades afloram na mente do indivíduo, aparece a dúvida que não existia antes e ele perde a "inocência" das crianças, não sendo mais capaz de raciocinar por meio de imagens. Talvez, o adulto tenha a pretensão de oferecer uma resposta geral, independente do conteúdo. Podemos dizer que há, então, uma espécie de regressão. Uma regressão que consideramos aparente, uma vez que o modo de raciocinar do adulto aponta para formas mais complexas de raciocínio, nas quais está presente explicitamente a lógica proposicional ${ }^{4}$.

Dados a partir dos questionário podem reforçar nossa argumentação. Para tanto, vale a pena mencionar o desempenho dos sujeitos num outro tipo de questão que, por ser diferente das demais, tanto no seu enunciado como nos seus resultados, não aparece no Anexo. Tratase da questão abaixo, que apresenta diversos enunciados, os quais podem ou não ter equivalência do ponto de vista lógico. A dificuldade de solução é tão grande que não houve um adulto sequer que a tenha respondido inteiramente correta:

Diga quais frases são equivalentes entre si:

- Tudo que é pequeno bóia.

- Só é pequeno se bóia.

- Só bóia se for pequeno.

- Se for pequeno então bóia.

- É pequeno porque bóia.

- Se bóia então é pequeno.

\footnotetext{
${ }^{4}$ A esse respeito, vale a pena relatar certa confusão das entrevistadoras na apresentação da hipótese As coisas bóiam porque têm muita água. Num primeiro momento, elas apresentaram o enunciado: As coisas bóiam porque têm muita água. Algumas vezes, por exigências de melhor compreensão do enunciado, era necessária a sua repetição que, por iniciativa das entrevistadoras, foi apresentado na forma de uma pergunta. No entanto, na maioria das vezes, as entrevistadoras, com a pergunta, mudaram o sentido do enunciado original: Se tivesse pouca água as coisas também boiariam? A pergunta, na verdade, é a negação, do ponto de vista da lógica, do enunciado original. Enquanto o falseador do enunciado é um objeto que mesmo com muita água afunda, o falseador da pergunta é um objeto que bóia mesmo com pouca água. Nossas entrevistadoras foram treinadas no sentido de diferenciar uma condicional de uma condicional inversa, uma vez que também participaram do processo de elaboração das entrevistas. No entanto, na situação coloquial na qual se dá a entrevista, não conseguiram percorrer, com a rapidez que a situação exigia, o caminho mais complexo. Por outro lado, o mais simples estava impedido pela tomada de consciência da diferenciação acima. É bom ressaltar que, por conta dos enganos cometidos pelas entrevistadoras, foram realizadas mais nove entrevistas, somente relativa à parte que concerne à hipótese As coisas bóiam porque têm pouca água.
} 
- Tudo que é pequeno bóia.

- Bóia porque é pequeno.

Para resolvê-la, é necessário comparar esses enunciados (nessa questão, essas comparações são múltiplas) e, portanto, percorrer caminhos muito complexos do ponto de vista lógico. De acordo com nossa interpretação, não há, nessa questão, a possibilidade de se "cortar o caminho" com um raciocínio mais simples, através de imagens.

\section{Estratégia versus forma das hipóteses}

A fim de testar a existência de relação entre enunciados com os conectivos tudo que e porque e os falseamentos corretos e incorretos através dos diversos domínios (oco, ave, pesado) em ambas as partes das questões (questões a e $b$ ), foram construídas seis tabelas de contingência. A TAB. 8 (e as cinco seguintes) apresenta as freqüências de falseamentos corretos e incorretos para ambos os conectivos, referentes ao domínio oco na questão a. Entre parênteses, encontra-se o percentual de falseamentos corretos e incorretos. Utilizou-se como medida da intensidade da relação entre o tipo de conectivo e o tipo de falseamento o Coeficiente de Contingência ${ }^{5}-\mathrm{C}$ - (Siegel, 1975); todos os cálculos foram efetuados com o programa "SPSS for Windows - Release 10.0".

TABELA 8 - Falseamentos corretos e incorretos para os dois conectivos na parte a) da questão do domínio oco

\begin{tabular}{|c|c|c|c|c|}
\hline & \multicolumn{2}{|c|}{ Tudo que } & \multicolumn{2}{c|}{ Porque } \\
\hline & & $\%$ & & $\%$ \\
\hline correto & 7 & 20,0 & 28 & 68,3 \\
\hline incorreto & 28 & 80,0 & 13 & 31,7 \\
\hline
\end{tabular}

$\mathrm{C}=0,435$ (nível de significância estatística: 0,000)

Conforme apresentado na TAB. 8, efetivamente há alguma relação entre o tipo de conectivo e o tipo de falseamento, pois $C=0,435$ e é estatisticamente significativo em nível menor do que 0,05. A seguir, são apresentadas as demais tabelas.

5 O Coeficiente de Contingência é uma medida da relação entre variáveis nominais (aqui as variáveis são o tipo de conectivo e o tipo de falseamento), resultando em um valor igual ou maior do que zero e menor do que um. Caso as variáveis não estejam relacionadas (sejam independentes ou ortogonais), o coeficiente será nulo; coeficientes altos (próximos da unidade) identificam variáveis muito relacionadas. O nível de significância estatística é a probabilidade de que a amostra que serviu de base para o cálculo do coeficiente tenha vindo de uma população onde o Coeficiente de Contingência é nulo; dessa forma, se o nível de significância estatística for baixo (usualmente inferior a 0,05), acreditar-se-á que a amostra em questão não é originária de uma população onde ambas as variáveis são independentes. 
TABELA 9 - Falseamentos corretos e incorretos para os dois conectivos na parte b) da questão do domínio oco

\begin{tabular}{|c|c|c|c|c|}
\hline & \multicolumn{2}{|c|}{ Tudo que } & \multicolumn{2}{c|}{ Porque } \\
\hline & & $\%$ & & $\%$ \\
\hline correto & 26 & 34,7 & 71 & 79,8 \\
\hline incorreto & 49 & 65,3 & 18 & 20,2 \\
\hline
\end{tabular}

$\mathrm{C}=0,416$ (nível de significância estatística: 0,000)

TABELA 10 - Falseamentos corretos e incorretos para os dois conectivos na parte a) da questão do domínio ave

\begin{tabular}{|l|c|c|c|c|}
\hline & \multicolumn{2}{|c|}{ Tudo que } & \multicolumn{2}{c|}{ Porque } \\
\hline & & $\%$ & & $\%$ \\
\hline correto & 14 & 18,4 & 56 & 83,6 \\
\hline incorreto & 62 & 81,6 & 11 & 16,4 \\
\hline
\end{tabular}

$\mathrm{C}=0,543$ (nível de significância estatística: 0,000)

TABELA 11 - Falseamentos corretos e incorretos para os dois conectivos na parte b) da questão do domínio ave

\begin{tabular}{|c|c|c|c|c|}
\hline & \multicolumn{2}{|c|}{ Tudo que } & \multicolumn{2}{c|}{ Porque } \\
\hline & & $\%$ & & $\%$ \\
\hline Correto & 22 & 27,5 & 72 & 90,0 \\
\hline incorreto & 58 & 72,5 & 8 & 10,0 \\
\hline
\end{tabular}

$\mathrm{C}=0,536$ (nível de significância estatística: 0,000)

TABELA 12 - Falseamentos corretos e incorretos para os dois conectivos na questão a) do domínio pesado

\begin{tabular}{|c|c|c|c|c|}
\hline & \multicolumn{2}{|l|}{ Tudo que } & \multicolumn{2}{c|}{ Porque } \\
\hline & & $\%$ & & $\%$ \\
\hline correto & 5 & 8,6 & 14 & 23,0 \\
\hline incorreto & 53 & 91,4 & 47 & 77,0 \\
\hline
\end{tabular}

$\mathrm{C}=0,192$ (nível de significância estatística: 0,033) 
TABELA 13 - Falseamentos corretos e incorretos para os dois conectivos na parte b) da questão do domínio pesado

\begin{tabular}{|c|c|c|c|c|}
\hline & \multicolumn{2}{|c|}{ Tudo que } & \multicolumn{2}{c|}{ Porque } \\
\hline correto & & $\%$ & & $\%$ \\
\hline incorreto & 54 & 49,5 & 46 & 56,8 \\
\hline
\end{tabular}

$\mathrm{C}=0,072$ (nível de significância estatística: 0,322)

Inspecionando-se essas seis tabelas, constata-se haver alguma relação entre o tipo de conectivo utilizado e o tipo de falseamento: em todas elas a percentagem de falseamentos corretos é maior em Tudo que do que em Porque, levando a Coeficientes de Contingência superiores a 0,4 com duas exceções. Nas TAB. 12 e 13, os coeficientes são menores, sendo o último sem significância estatística (nível de significância superior a 0,05). Dessa forma, os conectivos com nexos causais parecem introduzir dificuldades maiores no falseamento das hipóteses.

\section{Estratégias versus conteúdo das hipóteses}

A fim de investigar a existência de relação entre o tipo de estratégia utilizada pelos sujeitos e os conteúdos das hipóteses (TAB. 2 a 5), construiu-se a TAB. 14. Nesta, as estratégias foram categorizadas em três tipos apenas: verificação, falseamento (correto ou incorreto) e outra. A freqüência com a qual cada estratégia ocorreu para cada uma das hipóteses, bem como o respectivo percentual são apresentados.

O Coeficiente de Contingência, nesse caso, resultou em 0,508 (estatisticamente significativo em nível inferior a 0,05), mostrando haver relação entre o tipo de estratégia e 0 conteúdo das hipóteses.

TABELA 14 - Estratégias relativas às hipóteses e ao conteúdo das hipóteses

\begin{tabular}{|c|c|c|c|c|c|c|}
\hline & \multicolumn{2}{|c|}{ Verificação } & \multicolumn{2}{|c|}{ Falseamento } & \multicolumn{2}{|c|}{ Outra } \\
\hline & & $\%$ & & $\%$ & & $\%$ \\
\hline As coisas bóiam porque pesam pouco & 11 & 61,1 & 1 & 4,2 & 8 & 21,1 \\
\hline As coisas bóiam porque são pequenas & 3 & 16,7 & 11 & 45,8 & 6 & 15,8 \\
\hline As coisas bóiam porque são ocas & 4 & 22,2 & 7 & 29,2 & 9 & 23,7 \\
\hline As coisas bóiam porque têm muita água & 0 & 0,0 & 5 & 20,8 & 15 & 39,5 \\
\hline
\end{tabular}

$\mathrm{C}=0,508$ (nível de significância estatística: 0,000)

Para a hipótese As coisas bóiam porque pesam pouco, ocorreu uma maior incidência na verificação, o que tem a ver, segundo Carretero (1979:12), com o fato de que "as idéias espontâneas do sujeito sobre o fenômeno da flutuação têm favorecido uma tendência a verificar aquelas hipóteses cujo conteúdo é idêntico ou similar a essas idéias". A similaridade dessa hipótese com as idéias dos sujeitos pode ser observada na TAB. 1. Por outro lado, as 
estratégias de falseamento, seja correto ou incorreto, aparecem com maior incidência na hipótese As coisas bóiam porque são pequenas, que é uma explicação praticamente desconsiderada pelos sujeitos (vide a TAB. 1). Pode-se visualizar a relação entre as estratégias utilizadas e os conteúdos das hipóteses, procedendo-se a uma Análise de Correspondência ${ }^{6}$ (Escotier e Pagès, 1990) com a TAB. 14. A figura 1 apresenta o mapeamento bidimensional obtido a partir da TAB. 14 com o programa "SPSS for Windows - Reelase 10.0".

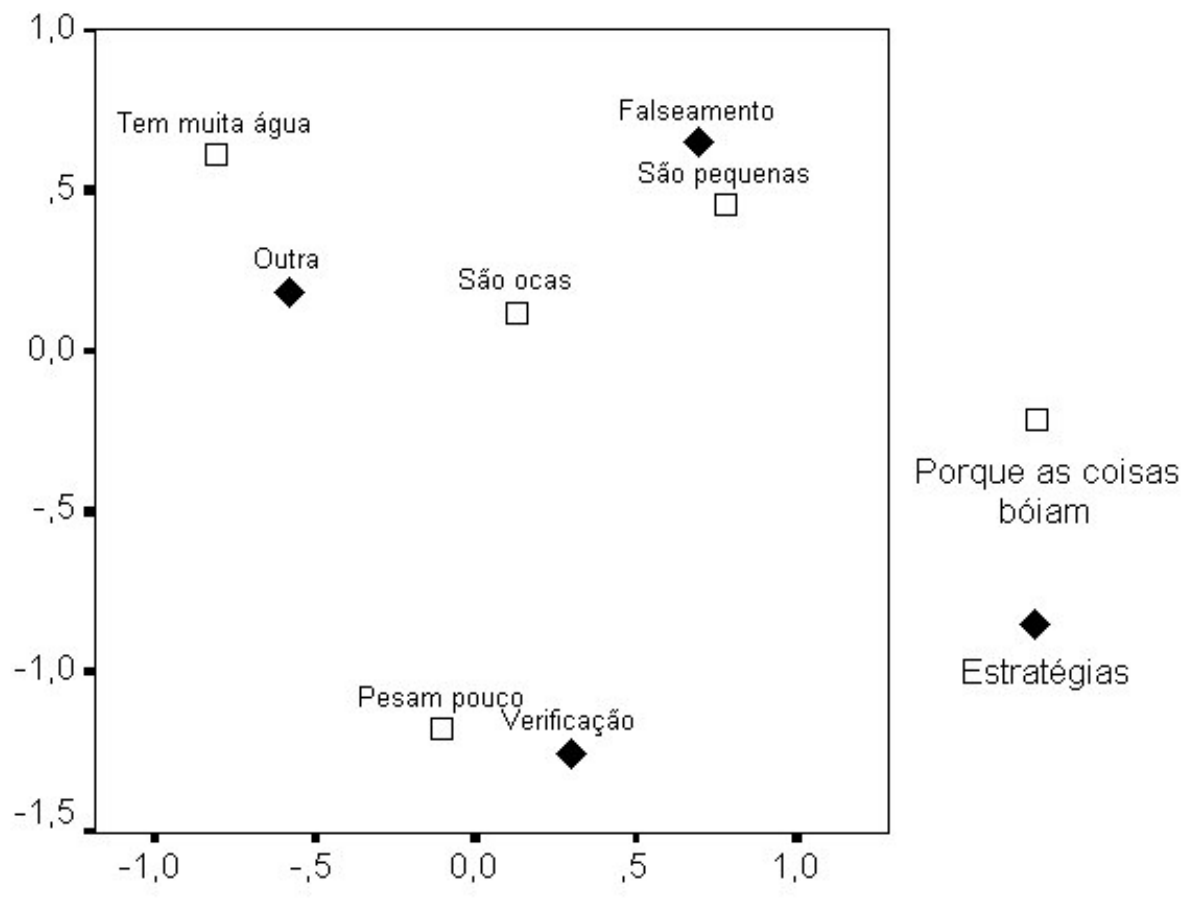

FIGURA 1 - Mapeamento bidimensional das estratégias e dos conteúdos das hipóteses produzido por uma análise de correspondência

Conforme já notado anteriormente pela inspeção da TAB. 14, observa-se, na figura 1, similaridade entre a verificação e a hipótese As coisas bóiam porque pesam pouco, bem como entre falseamento e a hipótese As coisas bóiam porque são pequenas.

\section{CONCLUSÕES}

Alguns autores têm mostrado que a capacidade de comprovar hipóteses "está mediatizada pelo conteúdo da tarefa a ser realizada, o que vai de encontro ao que postulam os enfoques sintáticos sobre o raciocínio humano" (Baillo e Carretero 1996:90). A partir da perspectiva da Psicologia Cognitiva, Pozo (1988), em seu interessante artigo intitulado "Das

6 Tal procedimento mapeia, em um espaço multidimensional (usualmente com duas dimensões), as similaridades entre as categorias das variáveis nominais, permitindo entender o significado da relação entre elas. 
tormentosas relações entre forma e conteúdo no pensamento: crônica de um romance anunciado", aponta vários aspectos que dariam conta da influência do conteúdo de uma tarefa sobre o raciocínio: nexos causais, diferentes domínios do conhecimento, familiaridade e idéias prévias.

Com o questionário, pudemos constatar que a capacidade de falsear corretamente hipóteses diminuía no caso de o enunciado apresentar nexo causal (na forma de porque), quando comparado com enunciado na forma tudo que. Em relação à diferença de domínio de conhecimento, tarefas naturais (ave-voa) e tarefas científicas (afunda-pesado-oco), acreditamos que novos estudos seriam necessários para oferecer respostas mais conclusivas.

No caso específico das estratégias de falseamento propostas por Carretero, a preferência pela verificação ou pelo falseamento de uma hipótese está fortemente marcada pelas idéias prévias. Baillo e Carretero (1996:90) crêem que a influência do conteúdo sobre a escolha das estratégias de raciocínio não são explicadas pelo "caracter concreto da tarefa, nem pela existência de esquemas pragmáticos de raciocínio causal, mas pelo conhecimento que possua o sujeito sobre o domínio em que se raciocina". Nossos dados sobre a correlação entre a estratégia de verificação e de falseamento, correto ou incorreto, com respeito às hipóteses as coisas bóiam porque são pequenas e as coisas bóiam porque pesam pouco, respectivamente, foram explicadas de acordo com essa idéia.

Há, ainda, a se considerar a questão etária. Vários autores, a começar por aqueles oriundos da escola de Genebra (Karmiloff-Smith e Inhelder 1974), apontam para o fato de que, antes da adolescência, os indivíduos possuem capacidade de utilizar estratégias de falseamento correto para comprovar hipóteses. Nossos dados também revelam esse fato. Nossa explicação, ainda que tentativa, vai na direção das diferenças dos procedimentos mentais utilizados por crianças e adultos. Se comparadas com os adultos, as crianças fariam uso de uma espécie de "atalho", fortemente favorecidos pelo domínio do conteúdo da tarefa. Os adultos, pretendendo uma resposta genérica, desvinculada do conteúdo, perder-se-iam nas inúmeras possibilidades de soluções para a tarefa proposta. Os resultados obtidos com adultos sobre o questionário confirmam nossa interpretação.

Nosso trabalho focalizou a precocidade do falseamento de hipóteses. O ensino de ciências fica em muito ampliado, no que diz respeito ao seu espectro de atuação, quando se consideram tais resultados. Crianças pertencentes à faixa etária dos 7-9 anos, que, em geral, têm sua aprendizagem reduzida à observação de fenômenos, podem nessa perspectiva entrar em contato com outras facetas da atividade científica.

Finalmente, concluímos este trabalho ressaltando que as relações de subordinação entre conteúdo e forma, ou entre o aspecto semântico e o sintático, ou entre o conteúdo e o aspecto lógico-matemático das tarefas são importantes para a atividade científica, pelo menos no que diz respeito à capacidade de eliminar hipóteses. Estudos que possam esclarecer tais subordinações são relevantes para o entendimento da atividade científica, bem como do ensino de ciências. Em consonância com a literatura na área, o presente trabalho enfatizou a influência do conteúdo, no que diz respeito ao conhecimento do sujeito sobre o domínio da tarefa, sobre o raciocínio hipotético-dedutivo. Concordamos com Baillo e Carretero (1996:91) quando afirmam: "Na medida em que a educação é responsável pelo dito conhecimento, podemos dizer, 
portanto, que o ensino possui também uma enorme influência sobre a utilização do método científico por parte dos alunos."

\section{Agradecimentos}

Agradeço as valiosas contribuições dos pareceristas, principalmente no que se refere ao tratamento estatístico dos dados. 


\section{Anexo - perguntas do questionário}

1a. As coisas bóiam porque são ocas. Você acha que essa afirmação é verdadeira ou falsa? Justifique.

1b. Para saber se a questão anterior é falsa você procuraria:

a) Objetos ocos que afundam

b) Objetos maciços que bóiam

c) Qualquer um dos dois

2a. Você acha que a afirmação Tudo que é pesado afunda é verdadeira ou falsa? Justifique.

2b. Para saber se a questão anterior é falsa você procuraria:

a) Objetos pesados que bóiam

b) Objetos leves que afundam

c) Qualquer um dos dois

3a. Você acha que a afirmação $E$ ave porque voa é verdadeira ou falsa? Justifique.

3b. Para saber se a questão anterior é falsa você procuraria:

a) Aves que não voam

b) Não-aves que voam

c) Qualquer um dos dois

4a. Você acha que a afirmação Tudo que é oco bóia é verdadeira ou falsa? Justifique.

4b. Para saber se a questão anterior é falsa você procuraria:

a) Objetos ocos que afundam

b) Objetos maciços que bóiam

c) Qualquer um dos dois

5a. Você acha que a afirmação Tudo que voa é ave é verdadeira ou falsa? Justifique.

5b. Para saber se a questão anterior é falsa você procuraria:

a) Aves que não voam

b) Não-aves que voam

c) Qualquer um dos dois

6a. Você acha que a afirmação Afunda porque é pesado é verdadeira ou falsa? Justifique. 
6b. Para saber se a questão é falsa você procuraria:

a) Objetos pesados que bóiam

b) Objetos leves que afundam

c) Qualquer um dos dois

\section{Referências}

Baillo, M., Carretero, M.(1996). Desarrollo del pensamiento y cambio conceptual en la comprensión de la flotación. In: Carretero, M. (org). Construir y Enseñar las Ciencias Experimentales. Buenos Aires: Aique Grupo Editor SA. p.77-106.

Carretero, M. (1979). ?Por qué flotan las cosas? El Desarrollo del Pensamiento HipotéticoDeductivo y la Ensenanza de la Ciencia. Infancia y Aprendizaje, n.8, p.7-22.

Carretero, M. (1980). Desarrollo intelectual durante la adolescencia: competencia, actuación y diferencias individuales. Infancia y Aprendizaje, n12, p.81-95.

Carretero, M. (1984). De la Larga Distancia que separa la Suposición de la Certeza. In: Carretero, M., García Madruga, J. A. (orgs). Lecturas de Psicología del Pensamiento, Razonamiento, Solución de Problemas y Desarrollo Cognitivo. Madrid: Alianza. p.321-338.

Castorina, J. A. (1985). Reflexiones sobre la formación y el alcance del pensamiento formal. In: Ortega, S. E. (org). Adolescencia: de la metapsicología a la clínica p.100-127.

Dibar Ure, M. C., Castorina, J. A. (1989). Algumas Reflexiones sobre la Relación entre Hipóteses y Procedimentos en la Física Infantil. In: Problemas en Psicología Genética. Buenos Aires: Miño y Dávila Editores. p.157-170.

Escotier, B., Pagès, J. (1990). Análisis factoriales simples y múltiples. Paris: Dunod.

Lawson, A. E., Renner, J. W. (1974). Should theoretical concepts be taught before formal operations? Science Education, v.61, n1, p.123-5.

Piaget, J. (1973). La Causalidad Física en el Niño. Madrid: Morata. (Tradução de: La representation du monde chez l'enfant, 1927).

Piaget, J. e Inhelder, B. (1967). De la Lógica de Niño a la Lógica del adolescente. Buenos Aires: Paidós. (Tradução de: De la Logique de l'enfant a la logique de L'adolescent, 1955).

Pozo, J. I. (1987). Del pensamiento formal a las concepciones espontáneas: qué cambia en la ensenanza de la ciencia? Infancia y Aprendizaje, n.38, p.35-52.

Pozo, J. I. (1988). De las tormentosas relaciones entre forma e contenido en el pensamiento: crónica de un romance anunciado. Estudios de Psicología, v.35, p.117-35.

Siegel, S. (1975). Estatística não-paramétrica. São Paulo: McGraw-Hill. 
Abstract: This paper reports a study on the strategies one adopts when challenged to put forward hypotheses related to the phenomenon of floating. Data presented has been obtained in interviews with children and questionnaires with adults. The strategies adopted by these people were analysed in relation with their age, the form of their hypotheses and the content of these. The correct falseability strategy is precociously adopted apparently due to the differences between the mental procedures of children and adults. Statistical analyses of data point to some relationship between the strategies adopted and characteristics of hypotheses put forward. Contributions to science education are indicated.

\section{Correspondência:}

Prof $^{a}$. Sonia Krapas, Instituto de Física, Universidade Federal Fluminense. Av. General Milton Tavares de Souza, s/ no - Niterói, RJ - cep 24210-340. Correio eletrônico: sonia@if.uff.br

Submetido em 29/06/1998, aceito para publicação em 29/01/2000. 